\title{
Control of gluconeogenesis in rat liver cells
}

\author{
Flux control coefficients of the enzymes in the gluconeogenic pathway in the absence and presence \\ of glucagon
}

\author{
Albert K. GROEN, ${ }^{*}$ Carlo W. T. vAN ROERMUND, Richard C. VERVOORN and Joseph M. TAGER \\ Laboratory of Biochemistry, University of Amsterdam, P.O. Box 20151, 1000 HD Amsterdam, The Netherlands
}

\begin{abstract}
We have used control analysis to quantify the distribution of control in the gluconeogenic pathway in liver cells from starved rats. Lactate and pyruvate were used as gluconeogenic substrates. The flux control coefficients of the various enzymes in the gluconeogenic pathway were calculated from the elasticity coefficients of the enzymes towards their substrates and products and the fluxes through the different branches in the pathway. The elasticity coefficients were either calculated from $\Gamma / K_{\text {eq. }}$ ratios (where $\Gamma$ is the mass-action ratio and $K_{\text {eq. }}$ is the equilibrium constant) and enzyme-kinetic data or measured experimentally. It is concluded that the gluconeogenic enzyme pyruvate carboxylase and the glycolytic enzyme pyruvate kinase play a central role in control of gluconeogenesis. If pyruvate kinase is inactive, gluconeogenic flux from lactate is largely controlled by pyruvate carboxylase. The low elasticity coefficient of pyruvate carboxylase towards its product oxaloacetate minimizes control by steps in the gluconeogenic pathway located after pyruvate carboxylase. This situation occurs when maximal gluconeogenic flux is required, i.e. in the presence of glucagon. In the absence of the hormone, when pyruvate kinase is active, control of gluconeogenesis is distributed among many steps, including pyruvate carboxylase, pyruvate kinase, fructose-1,6-bisphosphatase and also steps outside the classic gluconeogenic pathway such as the adenine-nucleotide translocator.
\end{abstract}

\section{INTRODUCTION}

Although gluconeogenesis in the liver is one of the most thoroughly studied metabolic pathways [see Hue (1981), Hers \& Hue (1983) and Friedmann (1984) for recent reviews], relatively little is known about control of flux through the pathway under physiological conditions. One reason for this is that, so far, control of gluconeogenesis has been studied in a qualitative way only. Since gluconeogenesis can, in theory, be controlled at many sites and by more than one enzyme at the same time, a qualitative description of the control exerted by the gluconeogenic enzymes can easily lead to confusion.

In a previous paper (Groen et al., 1983) we showed that gluconeogenesis from lactate is, indeed, controlled by different steps at the same time. The data also suggested that the distribution of control strongly depends on the experimental conditions used.

In the present paper we show that the experimental approach employed previously (Groen et al., 1983) can be used to obtain a quantitative picture of the distribution of control in gluconeogenesis if control analysis as developed by Kacser \& Burns (1973) and Heinrich \& Rapoport (1974) is applied. Furthermore, we show that the use of control analysis provides insight into the mechanisms by means of which control on gluconeogenic flux is exerted.

\section{MATERIALS AND METHODS}

Rat liver parenchymal cells were isolated from 20-24 h-starved male Wistar rats $(200-300 \mathrm{~g})$ as described in Groen et al. $(1982 a)$.

Perifusions were carried out as described by Groen et al. $(1982 a)$.

In order to study the intracellular distribution of metabolites under each steady-state condition, the digitonin fractionation procedure (see Groen et al., 1983) was used. The 'total' amounts of intracellular metabolites were determined as described in Sips et al. (1980). The concentrations of PEP, 2-PGA, 3-PGA, dihydroxyacetone phosphate and Glc-6-P were measured in the 'total' fractions. The concentrations of malate, ATP, ADP and $P_{i}$ were determined in both the cytosolic and the mitochondrial fractions. Glucose, lactate, Pyr, 3-hydroxybutyrate and acetoacetate were measured in the perfusate. The concentration of mitochondrial OAA was calculated from the mitochondrial malate concentration and the 3-hydroxybutyrate/acetoacetate ratio, assuming equilibrium in the malate dehydrogenase and 3-hydroxybutyrate dehydrogenase reactions. The concentration of $\mathrm{OAA}_{\mathrm{c}}$ was calculated from the cytosolic malate concentration and the lactate/Pyr ratio, assuming equilibrium in the lactate dehydrogenase and cytosolic malate dehydrogenase reactions. The cytosolic GTP/GDP ratio

\footnotetext{
Abbreviations used: AT, adenine-nucleotide translocator; subscript c, cytosolic; Fru-6- $P$, fructose 6-phosphate; Fru-1,6- $P_{2}$, fructose 1,6bisphosphate; GAP, glyceraldehyde 3-phosphate; GAPDH, glyceraldehyde-3-phosphate dehydrogenase (EC 1.2.1.12); Glc-6-P, glucose 6-phosphate $\Gamma$, mass-action ratio; subscript $\mathrm{m}$, mitochondrial; OAA, oxaloacetate; PEP, phosphoenolpyruvate; PEPCK, phosphoenolpyruvate carboxykinase (EC 4.1.1.32); 2- and 3-PGA-, 2- and 3-phosphoglycerate; PGI, phosphoglucose isomerase (glucosephosphate isomerase) (EC 5.3.1.9); PGK, phosphoglycerate kinase (EC 2.7.2.3); PK, pyruvate kinase (EC 2.7.1.40); PGM, phosphoglycerate mutase (EC 5.4.2.1); PT, pyruvate-transport system; Pyr, pyruvate; TIM, triosephosphate isomerase (EC 5.3.1.1); $v_{\mathrm{f}}$, rate in the forward direction; $V_{\mathrm{F}}^{\prime}$, apparent maximal velocity in the forward direction; $\mathrm{v}_{\mathrm{r}}$, rate in the reverse direction; $V_{\mathrm{R}}^{\prime}$, apparent maximal velocity in the reverse direction.

* Present address: Division of Gastroenterology, Academic Medical Centre of the University of Amsterdam, Meibergdreef 9, 1105 AZ Amsterdam, The Netherlands.
} 


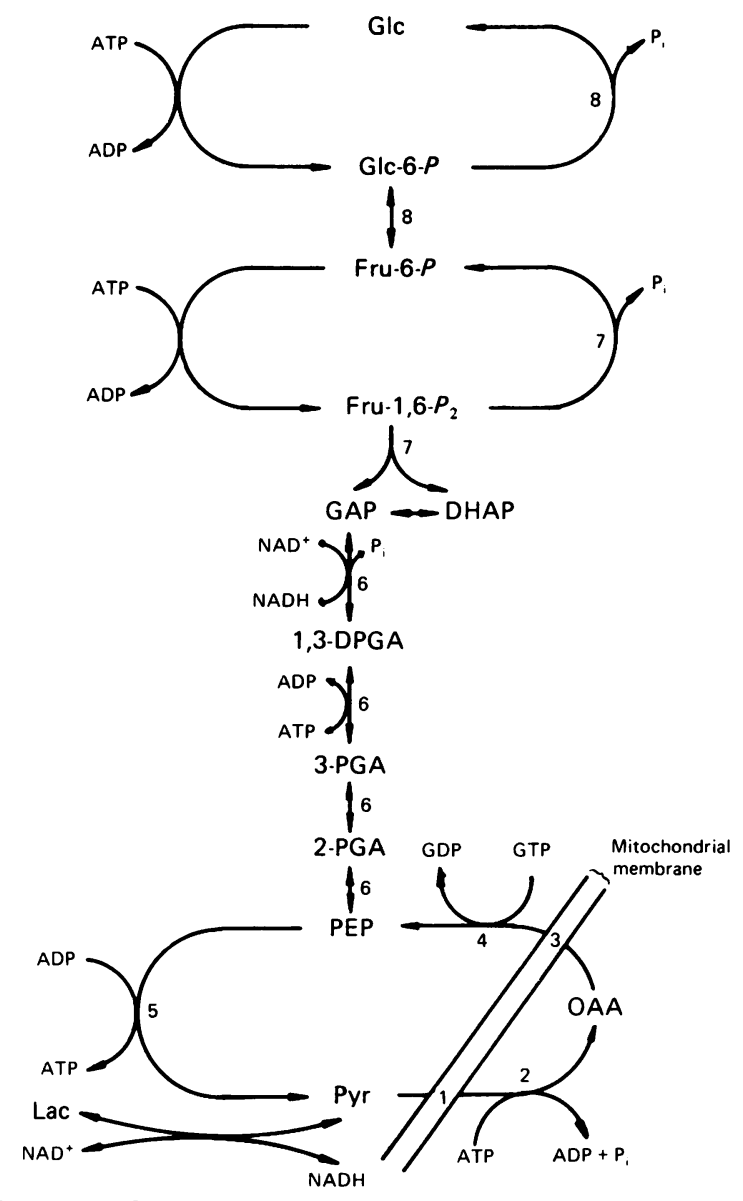

Scheme 1. Scheme of gluconeogenesis from lactate

Key to numbers: 1, mitochondrial Pyr translocator; 2, pyruvate carboxylase; 3 , steps involved in the transport of OAA from mitochondria to cytosol; 4, PEPCK ; 5, PK; 6, enolase/PGM/glyceraldehyde-3-phosphate dehydrogenase/PGK; 7, TIM/aldolase/fructose-1,6-bisphosphatase; 8, PGI/glucose-6-phosphatase. Extra abbreviations used: Glc, glucose; Lac, lactate; DHAP, dihydroxyacetone phosphate.

was calculated from the cytosolic ATP/ADP ratio, assuming equilibrium in the cytosolic nucleotide diphosphokinase reaction (Akerboom et al., 1979). The bicarbonate concentration in cytosol and mitochondrion was calculated from the extracellular concentration, assuming distribution of the metabolite according to the proton gradients, a cytosolic $\mathrm{pH}$ of 7.0 (Hoek et al., 1980) and mitochondrial pH of 7.4 (Tischler et al., 1977; Siess et al., 1978; Soboll et al., 1980). The values for the ratios between the mass-action ratio $(\Gamma)$ and the equilibrium constant $\left(K_{\text {eq. }}\right)\left(\Gamma / K_{\text {eq. }}\right)$ were calculated by using the equilibrium constants given by Lowry \& Passoneau (1964), Van der Meer et al. (1978), Wood et al. (1966), Atkinson et al. (1961) and Jomain-Baum et al. (1976).

Metabolites were determined by using standard enzymic methods (Bergmeyer, 1970; Williamson \& Corkey, 1969; Lowry \& Passoneau, 1971).

Collagenase (Type IV), lactate and glucagon were obtained from Sigma Chemical Co. (St. Louis, MO, U.S.A.), and other biochemicals were obtained from Boehringer (Mannheim, Germany).

\section{RESULTS}

In order to describe the distribution of control in the gluconeogenic pathway completely, all steps able to influence gluconeogenic flux should be taken into consideration. The scheme of gluconeogenesis from lactate (Scheme 1) should therefore be extended to include steps that could control gluconeogenesis indirectly by influencing the mitochondrial and cytosolic phosphate potentials, the cytosolic cyclic AMP concentration, ion gradients, etc. Direct assessment of the flux control coefficients of all these steps is at present impossible. However, all steps outside the classic gluconeogenic pathway eventually exert their influence on gluconeogenic flux via one or more of the steps depicted in Scheme 1. We will therefore begin with the determination of the flux control coefficients of the steps in Scheme 1. Next, the properties of the relevant enzymes will be discussed. An evaluation of possible flux control by steps outside the classic gluconeogenic pathway will then be greatly facilitated.

Relation between flux control coefficients and elasticity coefficients: the connectivity theorem

Central parameters in control analysis are the flux control coefficient and the elasticity coefficients of an enzyme [see Kacser \& Burns (1979) for definitions].

The flux control coefficient of an enzyme is a quantitative measure of the amount of control exerted by the enzyme on steady-state flux through a pathway.

There are as yet no suitable inhibitors available for a direct measurement of the flux control coefficients of most steps in the gluconeogenic pathway. An alternative method to determine flux control coefficients is to make use of the connectivity theorem developed by Kacser \& Burns (1973), which relates the flux control coefficients of adjacent enzymes to the elasticity coefficients of those enzymes to their common intermediate, i.e.:

$$
\sum_{j=1}^{n} C_{\mathrm{E}_{j}}^{J} \cdot \epsilon_{\mathrm{S}_{\mathrm{k}}}^{v_{\mathrm{j}}}=0
$$

where $C_{\mathrm{E}_{j}}^{J}$ is the flux control coefficient of step $j$ on $J$, the flux through the pathway, and $\epsilon_{\mathrm{S}_{\mathrm{k}}^{j}}^{v_{j}}$ is the elasticity coefficient of step $j$ towards the intermediate $S_{k}$.

In contrast with the flux control coefficient, the elasticity coefficient of an enzyme towards a substrate or product is a property of the isolated enzyme; it is a quantitative measure of the response of the enzyme to a change in the concentration of the substrate or product.

Applying the connectivity theorem to gluconeogenesis, the following equations can be derived, the numbers referring to the reactions in Scheme 1. Some of the reactions have been combined (see below). Glucokinase and phosphofructokinase were not taken into consideration since they are inactive under our experimental conditions (Groen et al., 1983).

$$
\begin{gathered}
\frac{C_{1}^{J}}{C_{2}^{J}}=\frac{-\epsilon_{\mathrm{Pyr}}^{2}}{\epsilon_{\mathrm{Pyr}}^{1}} \frac{C_{2}^{J}}{C_{3}^{J}}=\frac{-\epsilon_{\mathrm{OAA}_{\mathrm{m}}}^{3}}{\epsilon_{\mathrm{OAA}_{\mathrm{m}}}^{2}} \frac{C_{3}^{J}}{C_{4}^{J}}=\frac{-\epsilon_{\mathrm{OAA}_{\mathrm{c}}}^{4}}{\epsilon_{\mathrm{OAA}_{\mathrm{c}}}^{3}} \\
C_{4}^{J} \cdot \epsilon_{\mathrm{PEP}}^{4}+C_{5}^{J} \cdot \epsilon_{\mathrm{PEP}}^{5}+C_{6}^{J} \cdot \epsilon_{\mathrm{PEP}}^{6}=0 \\
\frac{C_{6}^{J}}{C_{7}^{J}}=\frac{-\epsilon_{\mathrm{GAP}}^{7}}{\epsilon_{\mathrm{GAP}}^{6}}, \frac{C_{7}^{J}}{C_{8}^{J}}=\frac{-\epsilon_{\mathrm{Glc}-6-P}^{8}}{\epsilon_{\mathrm{Glc}-6 \cdot P}^{7}}
\end{gathered}
$$


Table 1. Elasticity coefficients of the Pyr translocator towards $\mathbf{P y r}_{\mathbf{m}}$ and $\mathbf{P y r}_{\mathbf{c}}$ in liver cells isolated from starved rats

Cells $(25 \mathrm{mg} / \mathrm{ml})$ were incubated with $15 \mathrm{~mm}$-lactate, $3 \mathrm{~mm}$-Pyr and $2 \mathrm{~mm}$-oleate. After $15 \mathrm{~min}$ of incubation, cell samples were taken and fractionated by the digitonin technique. $\left[\mathrm{Pyr}_{\mathrm{c}}\right]$ was calculated from the difference between intracellular and mitochondrial contents. The $\Gamma / K_{\text {eq. }}$ ratio was calculated assuming a pH difference of 0.4 between the mitochondrial and cytosolic compartments. The $\Gamma / K_{\text {eq. }}$ ratios are given as means \pm S.E.M. for three different cell preparations. The elasticity coefficient was calculated as described in the text.

\begin{tabular}{|c|c|c|c|c|}
\hline \multirow{2}{*}{$\begin{array}{l}\text { [Pyr] } \\
(\mathrm{mM})\end{array}$} & \multirow{2}{*}{$\begin{array}{c}J_{\text {glucose }} \\
(\mu \mathrm{mol} / \mathrm{min} \text { per } \mathrm{g} \\
\text { dry wt. })\end{array}$} & \multicolumn{3}{|c|}{ Pyr translocator } \\
\hline & & $\Gamma / K_{\text {eq. }}$ & $\epsilon_{\mathbf{P y r}_{\mathrm{c}}}^{\mathrm{PT}}$ & $\epsilon_{\mathbf{P y r}_{\mathrm{m}}}^{\mathbf{P T}}$ \\
\hline 3 & $4.9 \pm 0.4$ & $0.86 \pm 0.11$ & 7.1 & -6.1 \\
\hline
\end{tabular}

\section{Determination of elasticity coefficients}

The elasticity coefficients of enzymes towards a substrate or product can be determined as follows. (1) They can be calculated from enzyme-kinetic parameters and the measured concentrations of substrates and products. (2) They can be measured experimentally. Although this is in theory difficult to accomplish, since only one substrate or product may be varied, in practice it turns out that many enzymes are almost insensitive to their products to that in such cases the elasticity coefficient for the substrate can be derived from a simple $v$-versus-[S] plot. (3) They can be calculated if it is possible to manipulate the pathway flux in two independent ways and if the change in the concentration of intermediary metabolites can be monitored (Kacser \& Burns, 1979).

The first method is particularly useful in practice. The elasticity coefficients of most enzymes can also be expressed as follows:

$$
\epsilon_{\mathrm{S}}^{v}=\frac{1}{1-\Gamma / K_{\mathrm{eq}}}-\frac{v_{\mathrm{f}}}{V_{\mathrm{F}}^{\prime}}
$$

and

$$
\epsilon_{\mathrm{p}}^{v}=-\frac{\Gamma / K_{\mathrm{eq} .}}{1-\Gamma / K_{\mathrm{eq} .}}-\frac{v_{\mathrm{r}}}{V_{\mathrm{R}}^{\prime}}
$$

Thus, if the $\Gamma / K_{\mathrm{eq}}$. ratio of an enzyme-catalysed reaction is lower than 0.01 , the elasticity coefficient of the enzyme to the subtrate or product is almost solely dependent on $v / V^{\prime}$, i.e. the extent to which the enzyme is saturated with its substrate or product. On the other hand, if an enzyme-catalysed reaction operates close to equilibrium $\left(\Gamma / K_{\text {eq. }}<0.5\right)$, the elasticity coefficient depends in practice only on the value of the $\Gamma / K_{\text {eq. }}$ ratio.

We have applied these three methods to estimate the elasticity coefficients of the different steps in gluconeogenesis towards their respective substrates and products. Since to our knowledge this is the first time that the methods proposed (Kacser \& Burns, 1979; Groen et al., $1982 c$; Kacser, 1983; Groen, 1984) to determine elasticity coefficients actually have been used in experimental practice, a detailed account of the procedures employed is given below.

\section{Elasticity coefficient of the Pyr translocator}

Because of binding compartmentation of Pyr at low concentrations of the substrate, we were able to measure [Pyr] in the different intracellular compartments only at high, saturating, concentrations of lactate and Pyr, and thus under conditions of maximal gluconeogenic flux

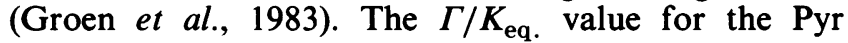

translocator was calculated by assuming a $\Delta \mathrm{pH}$ of 0.4 between cytosol and mitochondrion (Tischler et al., 1977; Siess et al., 1978; Soboll et al., 1980). The value obtained, 0.86 at $3 \mathrm{~mm}$-Pyr (Table 1), indicates that the Pyr translocator operates close to equilibrium under conditions of maximal gluconeogenic flux. Correspondingly the elasticity coefficients for $\mathrm{Pyr}_{\mathrm{c}}$ and $\mathrm{Pyr}_{\mathrm{m}}$ attain high values (Table 1).

In these experiments we did not determine the elasticity coefficients of the Pyr-transport system to $\mathrm{Pyr}_{\mathrm{m}}$ and $\mathrm{Pyr}_{\mathrm{c}}$ in the presence of glucagon. However, since glucagon exerts a stimulatory effect on Pyr transport (Adam \& Haynes, 1969; Halestrap, 1978; Allan et al., 1983), the elasticity coefficients of the Pyr-transport system to $\mathrm{Pyr}_{\mathrm{c}}$ and $\mathrm{Pyr}_{\mathrm{m}}$ will also be high in the presence of the hormone.

\section{Elasticity coefficient of pyruvate carboxylase}

Pyruvate carboxylase operates far from equilibrium under all conditions (Table $2 a$ ), so that the elasticity coefficient of the enzyme to Pyr is equal to $1-\left(v_{\mathrm{f}} / V_{\mathrm{F}}^{\prime}\right)$.

We have shown (Groen et al., 1983) that pyruvate carboxylase is the enzyme with the lowest apparent $V_{\max }$ in the pathway, $V_{\mathbf{F}}^{\prime}$ is therefore equal to $2 \times\left(J_{\text {glucose }}\right)_{\max .}+J_{\mathrm{PK}}$ [see Groen et al. (1983) for the method of calculation of PK flux $\left.\left(J_{\mathrm{PK}}\right)\right]$.

The rate through the reverse reaction, $v_{\mathrm{r}}$, can be neglected, so that the rate through the forward reaction $\left(v_{\mathrm{f}}\right)$ is equivalent to the net rate.

The elasticity coefficient of pyruvate carboxylase to mitochondrial OAA is equal to $1-\left(v_{\mathrm{r}} / V_{\mathrm{R}}^{\prime}\right)$. The $K_{\mathrm{m}}$ for OAA of chicken liver pyruvate carboxylase is $50 \mu \mathrm{M}$ (Barden et al., 1972). Assuming that the apparent $K_{\mathrm{m}}$ for OAA is the same under our experimental conditions, a maximal value of -0.04 for the elasticity coefficient of pyruvate carboxylase for $\mathrm{OAA}_{\mathrm{m}}$ was calculated at the highest lactate and Pyr concentrations. Since the value of this elasticity coefficient plays a crucial role in the distribution of flux control in the gluconeogenic pathway, we have checked the value by experimental measurement. For this purpose, rat liver cells were incubated with saturating concentrations of lactate and Pyr, $1 \mathrm{~mm}$-oleate and $1 \mu \mathrm{M}$-glucagon. The steady-state rate of gluconeogenesis was manipulated by adding different amounts of mercaptopicolinic acid, the non-competitive inhibitor of PEPCK (Jomain-Baum et al., 1976). In each incubation, $\left[\mathrm{OAA}_{\mathrm{m}}\right.$ ] was determined after digitonin fractionation of the cells. In Fig. 1 the flux through pyruvate carboxylase, as indicated by the rate of glucose formation, is plotted against [OAA]. It is clear that, initially, the flux through pyruvate carboxylase is not sensitive to $\left[\mathrm{OAA}_{m}\right]$, i.e., the elasticity coefficient of pyruvate carboxylase to $\mathrm{OAA}_{\mathrm{m}}$ is 
Table 2. Elasticity coefficients of the reactions in the gluconeogenic pathway towards their respective substrates and products

The elasticity coefficients for substrates and products were calculated as described in the text by using the values for the amounts of intermediates as given previously (Groen et al., 1983).

(a) Pyruvate carboxylase, PEPCK and the combined enolase/phosphoglucomutase/GAPDH reaction

\begin{tabular}{|c|c|c|c|c|c|c|c|c|c|c|}
\hline \multirow{2}{*}{$\begin{array}{l}\text { [Lactate] } \\
(\mathrm{mM})\end{array}$} & \multirow{2}{*}{$\begin{array}{c}J_{\text {glucose }} \\
(\mu \mathrm{mol} / \mathrm{min} \text { per } \mathrm{g} \\
\text { dry wt. })\end{array}$} & \multicolumn{3}{|c|}{ Pyruvate carboxylase } & \multicolumn{3}{|c|}{ PEPCK } & \multicolumn{3}{|c|}{ Enolase/PGM/GAPDH/PGK } \\
\hline & & $\Gamma / K_{\mathrm{eq}}$ & $\epsilon_{\mathrm{Pyr}}$ & $\epsilon_{\mathrm{OAA}_{\mathrm{m}}}$ & $\Gamma / K_{\text {eq. }}$ & $\epsilon_{\mathbf{O A A}_{\mathbf{c}}}$ & $\epsilon_{\mathrm{PEP}}$ & $\Gamma / K_{\mathrm{eq}}$ & $\epsilon_{\mathrm{PEP}}$ & $\epsilon_{\mathrm{GAP}}$ \\
\hline 1 & 2 & 3 & 4 & 5 & 6 & 7 & 8 & 9 & 10 & 11 \\
\hline \multicolumn{11}{|c|}{ Glucagon absent } \\
\hline 0 & 0.5 & $5.0 \times 10^{-3}$ & 0.97 & -0.005 & 0.09 & 1.1 & -0.12 & 1.18 & & \\
\hline 0.1 & 1.0 & $1.3 \times 10^{-3}$ & 0.90 & -0.002 & 0.06 & 0.97 & -0.09 & 1.27 & & \\
\hline 0.2 & 1.6 & $4.2 \times 10^{-4}$ & 0.79 & -0.002 & 0.03 & 0.89 & -0.07 & 1.02 & & \\
\hline 0.5 & 2.6 & $1.8 \times 10^{-4}$ & 0.58 & -0.002 & 0.03 & 0.78 & -0.09 & 0.74 & 3.9 & -2.9 \\
\hline 1 & 4.6 & $3.2 \times 10^{-4}$ & 0.24 & -0.007 & 0.02 & 0.54 & -0.10 & 0.72 & 3.6 & -2.6 \\
\hline 2 & 4.8 & $3.0 \times 10^{-4}$ & 0.13 & -0.02 & 0.02 & 0.50 & -0.11 & 0.53 & 2.1 & -1.1 \\
\hline 5 & 5.4 & $4.3 \times 10^{-4}$ & 0.05 & -0.04 & 0.01 & 0.35 & -0.09 & 0.51 & 2.0 & -1.0 \\
\hline \multicolumn{11}{|c|}{ Glucagon $(0.1 \mu \mathrm{M})$ present } \\
\hline 0 & 0.6 & $7.5 \times 10^{-3}$ & 0.94 & -0.008 & 0.1 & 1.1 & -0.12 & 1.94 & & \\
\hline 0.1 & 1.2 & $6.5 \times 10^{-3}$ & 0.87 & -0.003 & 0.04 & 0.94 & -0.07 & 1.50 & & \\
\hline 0.2 & 1.8 & $1.3 \times 10^{-3}$ & 0.78 & -0.004 & 0.03 & 0.88 & -0.07 & 1.7 & & \\
\hline 0.5 & 3.1 & $8.2 \times 10^{-4}$ & 0.62 & -0.006 & 0.04 & 0.78 & -0.12 & 0.69 & 2.8 & -1.8 \\
\hline 1 & 5.9 & $5.5 \times 10^{-4}$ & 0.29 & -0.02 & 0.02 & 0.53 & -0.13 & 0.80 & 5 & -4 \\
\hline 2 & 6.9 & $2.0 \times 10^{-4}$ & 0.16 & -0.02 & 0.02 & 0.45 & -0.15 & 0.87 & 7.7 & -6.7 \\
\hline 5 & 7.9 & $2.5 \times 10^{-4}$ & 0.05 & -0.04 & 0.01 & 0.35 & -0.16 & 0.73 & 3.7 & -2.7 \\
\hline
\end{tabular}

(b) Combined TIM, aldolase and fructose-1,6-bisphosphatase reaction, glucose-6-phosphatase and PK

\begin{tabular}{|c|c|c|c|c|c|c|c|c|}
\hline \multirow{2}{*}{$\begin{array}{l}\text { [Lactate] } \\
(\mathrm{mM})\end{array}$} & \multirow{2}{*}{$\begin{array}{c}J_{\text {glucose }} \\
\text { ( } \mu \mathrm{mol} / \mathrm{min} \text { per } \mathrm{g} \\
\text { dry wt.) }\end{array}$} & \multicolumn{3}{|c|}{$\begin{array}{l}\text { TIM/aldolase/fructose-1,6- } \\
\text { bisphosphatase }\end{array}$} & \multicolumn{2}{|c|}{ Glucose-6-phosphatase } & \multicolumn{2}{|c|}{ Pyruvate kinase } \\
\hline & & $\Gamma / K_{\mathrm{eq}}$ & $\epsilon_{\mathrm{GAP}}$ & $\epsilon_{\mathrm{Fru}-6-P}$ & $\Gamma / K_{\text {eq. }}$ & $\epsilon_{\mathrm{Glc}-6-P}$ & $\epsilon / K_{\text {eq. }}$ & $\epsilon_{\mathrm{PEP}}$ \\
\hline 1 & 2 & 3 & 4 & 5 & 6 & 7 & 8 & 9 \\
\hline \multicolumn{9}{|c|}{ Glucagon absent } \\
\hline 0 & 0.5 & $4.4 \times 10^{-9}$ & 1.9 & -0.01 & $3.1 \times 10^{-6}$ & 1 & $9.7 \times 10^{-7}$ & 0 \\
\hline 0.1 & 1.0 & $4.0 \times 10^{-9}$ & 2.2 & -0.01 & $4.0 \times 10^{-6}$ & 1 & $4.6 \times 10^{-6}$ & 3 \\
\hline 0.2 & 1.6 & $3.1 \times 10^{-9}$ & 3.1 & -0.02 & $5.4 \times 10^{-6}$ & 1 & $8.8 \times 10^{-6}$ & 4.5 \\
\hline 0.5 & 2.6 & $7.2 \times 10^{-9}$ & 4.1 & -0.04 & $4.1 \times 10^{-6}$ & 1 & $1.5 \times 10^{-5}$ & 4.5 \\
\hline 1 & 4.6 & $7.6 \times 10^{-9}$ & 3.9 & -0.07 & $2.9 \times 10^{-6}$ & 1 & $4.3 \times 10^{-5}$ & 2.9 \\
\hline 2 & 4.8 & $5.0 \times 10^{-9}$ & 1.8 & -0.07 & $2.1 \times 10^{-6}$ & 1 & $7.6 \times 10^{-5}$ & 3 \\
\hline 5 & 5.4 & $6.8 \times 10^{-9}$ & 1.2 & -0.08 & $1.5 \times 10^{-6}$ & 1 & $2.8 \times 10^{-4}$ & 3.5 \\
\hline \multicolumn{9}{|c|}{ Glucagon $(0.1 \mu \mathrm{M})$ present } \\
\hline 0 & 0.6 & $6.5 \times 10^{-9}$ & 1.9 & -0.01 & $6.9 \times 10^{-6}$ & 1 & $9.8 \times 10^{-7}$ & \\
\hline 0.1 & 1.2 & $4.1 \times 10^{-9}$ & 2.2 & -0.01 & $1.3 \times 10^{-5}$ & 1 & $2.7 \times 10^{-6}$ & \\
\hline 0.2 & 1.8 & $1.2 \times 10^{-8}$ & 2.5 & -0.02 & $9.3 \times 10^{-6}$ & 1 & $7.6 \times 10^{-6}$ & \\
\hline 0.5 & 3.1 & $1.5 \times 10^{-8}$ & 3.1 & -0.05 & $5.0 \times 10^{-6}$ & 1 & $9.5 \times 10^{-6}$ & \\
\hline 1 & 5.9 & $1.6 \times 10^{-8}$ & 0.91 & -0.09 & $3.9 \times 10^{-6}$ & 1 & $3.8 \times 10^{-5}$ & \\
\hline 2 & 6.9 & $4.4 \times 10^{-9}$ & 0.38 & -0.09 & $3.2 \times 10^{-6}$ & 1 & $6.7 \times 10^{-5}$ & \\
\hline 5 & 7.9 & $5.2 \times 10^{-8}$ & 0.29 & -0.11 & $2.9 \times 10^{-6}$ & 1 & $1.6 \times 10^{-4}$ & \\
\hline
\end{tabular}

low. The value for the elasticity coefficients determined from the initial slope of the curve in Fig. 1 is -0.05 , which is very close to the value of 0.04 calculated as described above.

\section{Elasticity coefficient of transport of oxaloacetate across the mitochondrial membrane}

Measurement of all components of the reactions involved in the transport of OAA from the mitochondrial to the cytosolic compartment via the malate/aspartate shuttle presents technical difficulties. We have therefore measured the elasticity coefficients of the overall reaction towards $\mathrm{OAA}_{\mathrm{m}}$ and $\mathrm{OAA}_{\mathrm{c}}$ as follows. Flux through the reactions was varied in two independent ways, either by increasing the rate of substrate supply (see Table 2 in Groen et al., 1983), or by inhibiting PEPCK with 3-mercaptopicolinic acid (see Fig. 1). The change in flux induced by either of the two methods can be written as a function of the elasticity coefficients of the overall reaction to $\mathrm{OAA}_{\mathrm{m}}$ and $\mathrm{OAA}_{\mathrm{c}}$.

$$
\frac{\mathrm{d} J}{J}=\epsilon_{\mathrm{OAA}_{\mathrm{m}}}^{3} \cdot \frac{\mathrm{dOAA}_{\mathrm{m}}}{\mathrm{OAA}_{\mathrm{m}}}+\epsilon_{\mathrm{OAA}_{\mathrm{c}}}^{3} \cdot \frac{\mathrm{dOAA}_{\mathrm{c}}}{\mathrm{OAA}_{\mathrm{c}}}
$$

The change in the flux through the reaction as monitored by gluconeogenic flux and the change in the concentration 


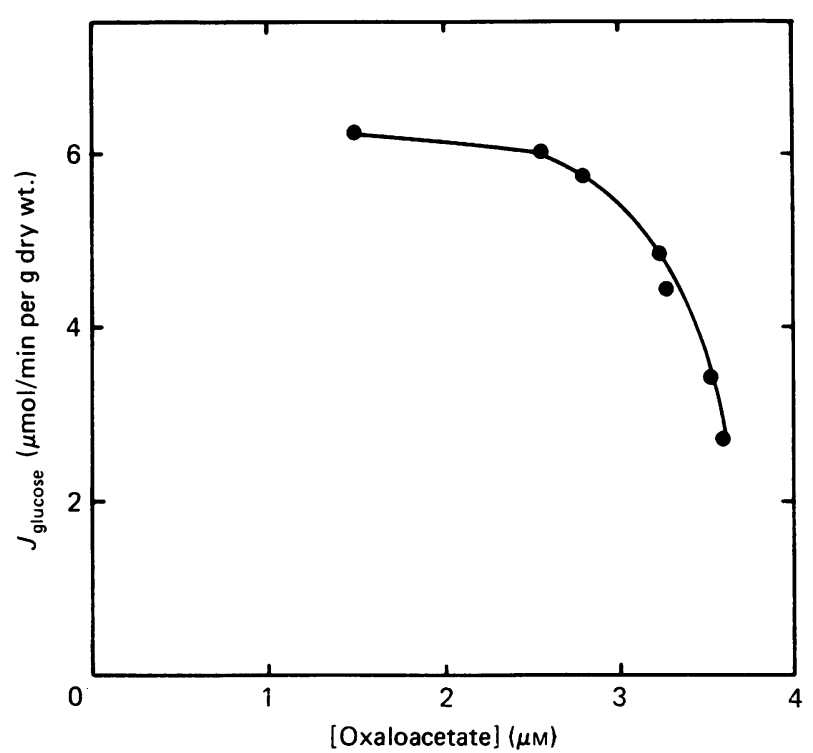

Fig. 1. Determination of the elasticity coefficient of pyruvate carboxylase to OAA

Rat liver cells ( $10 \mathrm{mg}$ dry $\mathrm{wt} . / \mathrm{ml})$ were incubated batchwise with $10 \mathrm{~mm}$-lactate, $1 \mathrm{~mm}$-Pyr, $1 \mathrm{~mm}$-oleate and $1 \mu \mathrm{M}$ glucagon for $30 \mathrm{~min}$ in the presence of different amounts of 3-mercaptopicolinic acid. Every $10 \mathrm{~min}$ a sample was taken for the determination of the rate of gluconeogenesis. At $t=30 \mathrm{~min}$, a cell sample was fractionated by the digitonin technique. The concentration of malate was determined in the mitochondrial fraction. The concentrations of 3-hydroxybutyrate and acetoacetate were measured in the extracellular fraction. $\left[\mathrm{OAA}_{m}\right]$ was calculated from the malate, 3-hydroxybutyrate and acetoacetate concentrations by assuming equilibrium in the malate dehydrogenase and 3-hydroxybutyrate dehydrogenase reactions.

of $\mathrm{OAA}_{\mathrm{m}}$ and $\mathrm{OAA}_{\mathrm{c}}$ were determined under both sets of conditions. Since two independent methods were used to manipulate the flux, two independent equations of the type given by eqn. (5) could be formulated from which the elasticity coefficients could be calculated. The values obtained were: $\epsilon_{\mathrm{OAA}_{\mathrm{m}}}^{3}=0.86$ and $\epsilon_{\mathrm{OAA}_{\mathrm{C}}}^{3}=-0.74$ for the conditions where lactate and Pyr were present in saturating concentrations in the presence of glucagon. In the absence of the hormone the method cannot be used, because of the substantial flux through pyruvate kinase under these conditions.

\section{Elasticity coefficient of PEPCK}

The elasticity coefficient of PEPCK to OAA was calculated from eqn. (3). The rate in the forward direction is given by the net rate plus the rate in the reverse direction: $v_{\mathrm{f}}=v+v_{\mathrm{r}}$. Since $v_{\mathrm{r}} / v_{\mathrm{f}}=\Gamma / K_{\mathrm{eq}}$. (Rolleston, 1972), the rate through the forward direction is given by:

$$
v_{\mathrm{f}}=\frac{v}{1-\Gamma / K_{\mathrm{eq}} .}=\frac{2 J_{\mathrm{glucose}}+J_{\mathrm{PK}}}{1-\Gamma / K_{\mathrm{eq}} .}
$$

The maximal velocity of PEPCK in the forward direction $\left(V_{\mathrm{F}}^{\prime}\right)$ was obtained from a Lineweaver-Burk plot of the data in Fig. 5(e) of Groen et al. (1983) (condition plus glucagon). $V_{\mathrm{F}}^{\prime}$ had a value of $24 \mu \mathrm{mol} / \mathrm{min} \cdot \mathrm{g}$ dry $\mathrm{wt}^{-1}$.
The elasticity coefficient of PEPCK for PEP was calculated from eqn. (4), assuming an apparent $K_{\mathrm{m}}$ of $1.2 \mathrm{~mm}$ (Jomain-Baum et al., 1976) of the enzyme for PEP.

\section{Elasticity coefficient of PK}

PK shows sigmoidal kinetics with respect to PEP under intracellular conditions. It is thus not possible to calculate the elasticity coefficient of the enzyme towards PEP from eqn. (3). We have therefore measured the elasticity coefficient directly under intracellular conditions as follows. The GAPDH/PGK couple operates near to thermodynamic equilibrium under gluconeogenic conditions (Groen et al., 1982b). It is therefore possible to vary the GAP/3-PGA ratio by changing the cytosolic redox state if the cytosolic phosphate potential is kept constant. Since PGM and enolase also operate near to equilibrium, changes in the 3-PGA concentration lead to corresponding changes in the PEP concentration. In Fig. 2, an experiment is shown in which rat liver cells were perifused with different concentrations of lactate at a constant [Pyr] of $0.5 \mathrm{~mm}$ in the presence or absence of $0.1 \mu \mathrm{M}$-glucagon. In the presence of the hormone, changing the lactate/Pyr ratio had only a small effect on $J_{\text {glucose. }}$ except at lactate/Pyr ratio of less than 4. However, in the absence of glucagon, a substantial inhibition of $J_{\text {glucose }}$ was observed as the lactate/Pyr ratio was decreased from 15 to 4 . Since Pyr was present at a saturating concentration under all conditions, the observed inhibition of gluconeogenesis $\left(\Delta J_{\text {glucose }}\right)$ must have been due to an increase

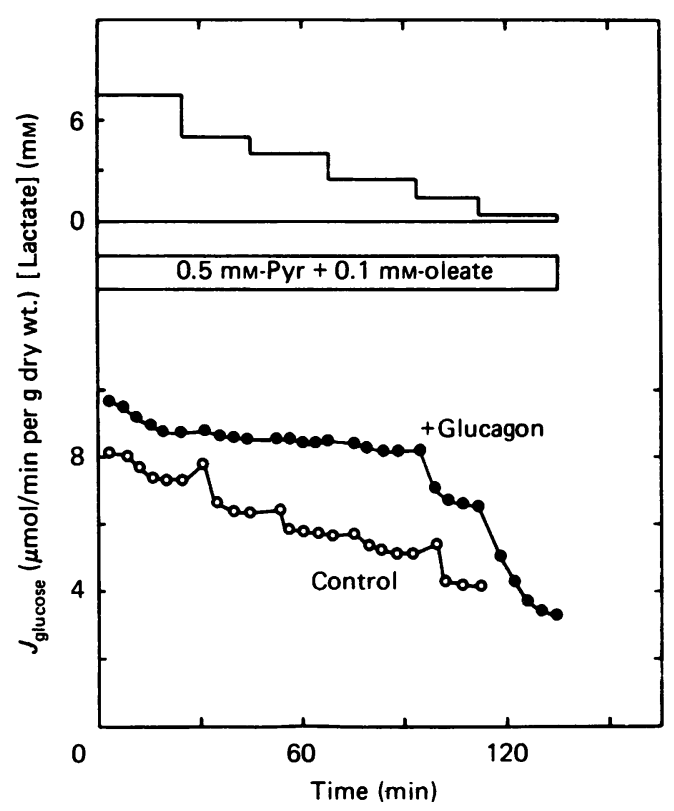

Fig. 2. Effect of the cytosolic redox state on gluconeogenesis from lactate and Pyr

Rat liver cells ( $200 \mathrm{mg}$ dry wt.) were perifused with different amounts of lactate in the presence of $0.5 \mathrm{mM}-\mathrm{Pyr}$ and $0.1 \mathrm{~mm}$-oleate, either with or without $0.1 \mu \mathrm{M}$-glucagon. In each steady state a sample of the cell suspension was taken for the determination of intracellular metabolites. The flow rate was $5.0 \mathrm{ml} / \mathrm{min}$. Glucose was assayed in the perifusate. 
in PK flux $\left(\Delta J_{\mathrm{PK}}\right)$ so that $\Delta J_{\text {glucose }}$ can be used to calculate $\Delta J_{\mathrm{PK}}$ :

$$
\Delta J_{\mathrm{PK}}=2 \Delta J_{\text {glucose }}
$$

In each steady state, PEP $_{\mathrm{c}}$ was determined. Fig. 3 shows the calculated $\Delta J_{\mathrm{PK}}$ in the presence of glucagon as a function of the $[\mathrm{PEP}]_{\mathrm{c}}$. The fitted curve crosses the $y$-axis between zero and $-0.2 \mu \mathrm{mol} / \mathrm{min}$ per $\mathrm{g}$ dry wt.

As has been shown in Groen et al. (1983), the stimulation of gluconeogenesis by glucagon can be almost completely accounted for by inhibition of PK flux. The $J_{\mathrm{PK}}$ in the absence of the hormone can therefore be estimated from the glucagon-induced increase in glucose formation and the PK flux in the presence of the hormone as follows:

$$
\begin{aligned}
\left(J_{\mathrm{PK}}\right)_{\text {control }}=2\left[\left(J_{\text {glucose }}\right)_{+ \text {glucagon }}\right. & \left.-\left(J_{\text {glucose }}\right)_{\text {control }}\right] \\
& +\left(J_{\mathrm{PK}}\right)_{+ \text {glucagon }}
\end{aligned}
$$

In Fig. 4 the values for $J_{\mathrm{PK}}$ in the absence of glucagon derived in this way have been plotted as a function of the cytosolic PEP concentration. Since, under these conditions, the concentrations of the other substrates and products of pyruvate kinase remain constant (results not shown), the elasticity coefficient of pyruvate kinase for phosphoenolpyruvate can be calculated from Fig. 4. The validity of this method is discussed in detail by Groen (1984).

Elasticity coefficients of the combined enolase, PGM, PGK and GAPDH reaction

For the sake of simplicity we have combined the near-equilibrium reactions located between PEP and GAP. Indeed, as shown in Table 1, the overall reaction is close to equilibrium under all conditions. At the lower gluconeogenic fluxes, in particular in the conditions plus glucagon, the $\Gamma / K_{\text {eq. }}$. values are higher than 1, indicating that the measured mass-action ratio may be somewhat overestimated. We have calculated the elasticity coefficients for PEP and GAP using eqns. (3) and (4). It can be easily shown that, in the case of near-equilibrium enzymes, these equations also hold for groups of enzymes (see also Fell \& Sauro, 1985).

\section{Elasticity coefficient of the combined TIM, aldolase and fructose-1,6-bisphosphatase reaction}

Since experimental measurement of the free concentrations of GAP and Fru-1,6- $P_{2}$ is hampered by compartmentation (Sols \& Marco, 1970), we have considered the steps that convert GAP into Fru-6-P as one reaction. The Fru-6-P concentration was calculated from the Glc-6- $P$ concentration by assuming equilibrium in the PGM reactions.

For the sake of simplicity we have assumed TIM to be in equilibrium under all conditions, so that the GAP concentration could be calculated from the DHAP concentration.

The elasticity coefficient of the combined TIM/aldolase/fructose-1,6-bisphosphatase reaction to GAP was derived in the following way. A fractional change in gluconeogenic flux, induced, for instance, by a change in the lactate-plus-Pyr concentration, can be written as a fractional change in the rate through the TIM/aldolase/fructose-1,6-bisphosphatase reaction, as follows:

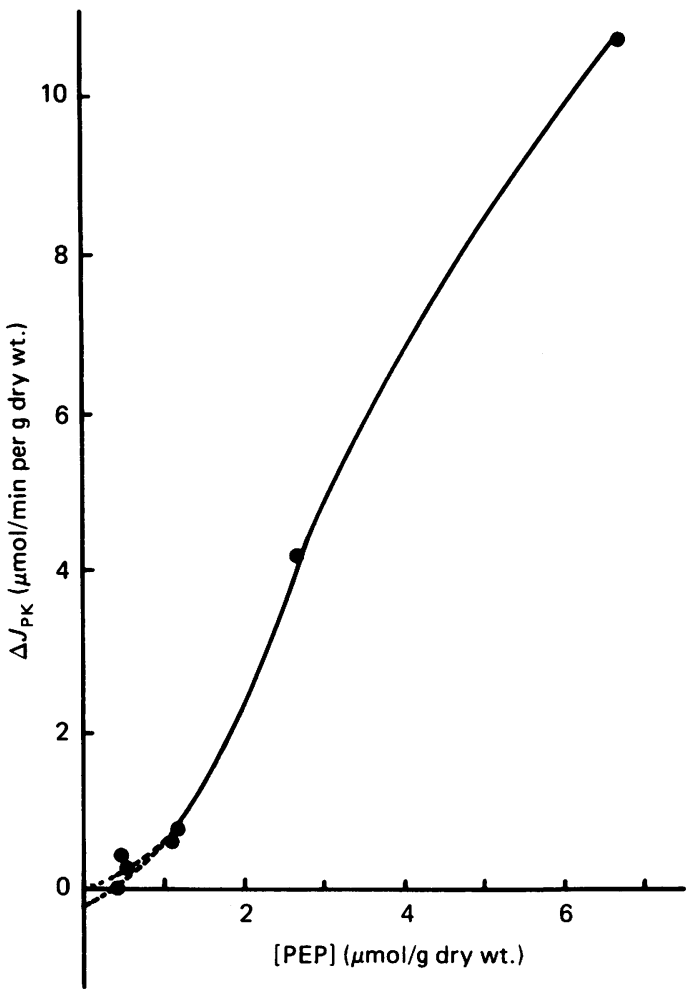

Fig. 3. Relationship between flux through pyruvate kinase and $\left[\right.$ PEP $_{\mathrm{c}}$ ] in the presence of glucagon

For experimental details, see the legend to Fig. 2. In each steady state of glucose formation a sample of the cell suspension was taken and fractionated by the digitonin technique. $\left[\mathrm{PEP}_{\mathrm{c}}\right]$ was determined. The increase in PK flux $\left(\Delta J_{P K}\right)$ in the presence of glucagon was calculated from the data in Fig. 2 as follows. In the first steady state of glucose formation in the presence of glucagon $(7.5 \mathrm{~mm}$ lactate), $\Delta J_{\mathrm{PK}}$ was taken to be zero. Since the observed inhibition of gluconeogenesis induced by lowering the lactate/pyruvate ratio must have been due to an increase in PK flux (see the text), $\Delta J_{\mathbf{P K}}$ in each steady state can be calculated by subtracting $J_{\text {glucose }}$ in that steady state from $J_{\text {glucose }}$ at 7.5 mM-lactate and multiplication of the difference by 2 . Note that, in this Figure only, the steady states in the presence of glucagon are considered. The curves were fitted by eye.

where 7 denotes TIM/aldolase/fructose-1,6-bisphosphatase. The concentration of $P_{i}$ was constant in the experiments of Table 2, and since $\epsilon_{\mathrm{Pi}}^{7}$ will also be low (Cassaza et al., 1979) the third term on the right-hand side of eqn. (8) can be neglected. Since fructose-1,6bisphosphatase operates far from equilibrium, the elasticity coefficient of the enzyme towards Fru-6-P is solely dependent on the degree to which the enzyme is saturated with its product. The $K_{\mathrm{i}}$ of the enzyme for Fru-6-P is $0.68 \mathrm{~mm}$ (Cassaza et al., 1979), and the maximal Fru-6-P concentration in the experiments in Table 2 was $35 \mu \mathrm{M}$. The maximal value of the elasticity coefficient of fructose-1,6-bisphosphatase towards Fru-6-P is therefore about 0.05 . The value for $\epsilon_{\mathrm{Fru}-6-P}^{7}$ in eqn. (8) will be approximately the same as the elasticity coefficient of fructose-1,6-bisphosphatase towards

$$
\mathrm{d} J_{\mathrm{Glc}} / J_{\mathrm{Glc}}=\epsilon_{\mathrm{GAP}}^{7} \cdot \mathrm{d}(\mathrm{GAP}) /(\mathrm{GAP})+\epsilon_{\mathrm{Fru}-6-P}^{7} \cdot \mathrm{d}\left(\text { Fru-6-P) } /(\text { Fru-6-P })+\epsilon_{\mathrm{P}_{\mathrm{i}}}^{7} \cdot \mathrm{d}\left(\mathbf{P}_{\mathrm{i}}\right) /\left(\mathbf{P}_{\mathrm{i}}\right)\right.
$$




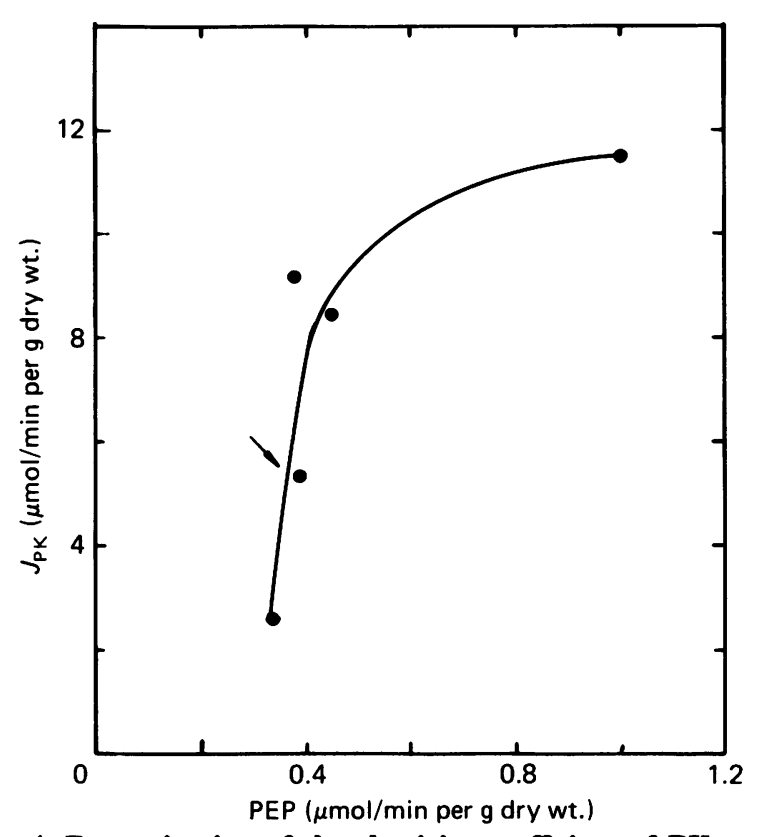

Fig. 4. Determination of the elasticity coeficient of $P K$ to the $\left[P E P_{c}\right]$ in the absence of glucagon

For experimental details, see the legend to Fig. 2. In each steady state of glucose formation a sample was taken from the cell suspension and fractionated by the digitonin technique. [PEP] in the cytosolic fraction was measured. The PK flux $\left(J_{\mathrm{PK}}\right)$ in each steady state of glucose formation was calculated from eqn. (7). The PK flux in the presence of glucagon $\left[\left(J_{\mathrm{PK}}\right)_{+\mathrm{glucagon}}\right]$ was calculated by assuming a $J_{\mathrm{PK}}$ in the first steady state of glucose formation in the presence of glucagon ( $7.5 \mathrm{mM}$-lactate) of $0.2 \mu \mathrm{mol} / \mathrm{min}$ per g dry wt. (see the text). The elasticity coefficient of PK to PEP was calculated at the point indicated by an arrow; this point was derived from the condition where the lactate/ pyruvate ratio was 10 ( $5 \mathrm{~mm}$-lactate).

Fru-6- $P$. Since $\mathrm{d}($ Fru-6- $P$ )/(Fru-6- $P$ ) is not very high either, the second term, too, on the right-hand side of eqn. (8) can be neglected. Consequently, by using eqn. (8), $\epsilon_{\mathrm{GAP}}^{7}$ can be calculated from Fig. $5(\mathrm{~b})$ of Groen et al. (1983), using DHAP to monitor the GAP concentration.

\section{Elasticity coefficient of PGI}

We were unable to measure the Fru-6-P concentration in our experiments. However, PGI has been shown to catalyse a near-equilibrium reaction under a variety of conditions (Williamson, 1965; Rolleston \& Newsholme, 1967; Williamson et al., 1969). We assume the reaction to be in equilibrium under our conditions.

\section{Elasticity coefficient of glucose-6-phosphatase}

The reaction catalysed by glucose-6-phosphatase is far from equilibrium under all conditions. The elasticity coefficient of glucose-6-phosphatase to Glc-6-P was calculated from eqn. (3). The Glc-6-P concentration was far below the $K_{\mathrm{m}}$ of the enzyme for Glc-6-P, so that the second term in eqn. (3) could be neglected. Consequently, the elasticity coefficient of glucose-6-phosphatase for Glc-6-P is about 1 under all conditions.

\section{Calculation of the flux control coefficients}

Substitution of the values for the elasticity coefficients given in Tables 1 and 2 in the equations grouped under eqn. (2) generates six linear equations with eight unknown factors. Because of the branch in the pathway at the PK step, the extra equation provided by the summation property $\left(\Sigma C_{\mathrm{E}_{\mathrm{i}}}=1\right.$; see Kacser \& Burns, 1973; Heinrich \& Rapoport, 1974) is not sufficient to allow calculation of the individual values of the flux control coefficients.

Kacser (1983) has shown that the ratio of the sum of the flux control coefficients of enzymes in branches of a pathway is equal to the ratio of the flux through the branches. Recently Fell \& Sauro (1985) have provided the formal proof for this relationship. When applied to gluconeogenesis:

$$
\frac{C_{1}^{J} \mathrm{Glc}+C_{2}^{J} \mathrm{Glc}+C_{3}^{J \mathrm{Glc}}+C_{4}^{J \mathrm{Glc}}}{C_{5}^{J} \mathrm{Glc}}=\frac{2 J_{\mathrm{Glc}}+J_{\mathrm{PK}}}{J_{\mathrm{PK}}}
$$

The numbers refer to the reactions shown in Scheme 1. This relationship provides the extra equation required. As shown by Fell \& Sauro (1985), an easy way to solve the resulting eight equations is to write them in matrix form. The first column of the inverted matrix gives the values for the flux control coefficients. The values for the flux control coefficients are given in Table 3. Control of flux is distributed between many steps. Major control is exerted by pyruvate carboxylase and, as expected, PK exerts negative control. Surprisingly, the near-equilibrium reactions located between PEP and GAP exert control. Their combined flux control coefficient is of the same order of magnitude as that of the combined TIM/aldolase/fructose-1,6- bisphosphatase reaction. The reason for the relatively high flux control by the near-equilibrium reactions is the high elasticity coefficient of PK for PEP. $A$ very small change in the PEP concentration will already lead to a change in PK flux and consequently gluconeogenic flux.

In the presence of glucagon, PK flux is close to zero (see above). As shown in Table 4 (column 2), the absence of PK activity causes a drastic shift in the distribution of control. The flux control coefficients of the steps between Pyr and PEP increase by about $50 \%$, whereas those of the steps after PEPCK greatly decrease. At saturating concentrations of lactate and Pyr, in the presence of glucagon, most of the control is exerted by pyruvate carboxylase. This is due to the very low elasticity coefficients of the enzyme towards Pyr and OAA under

Table 3. Distribution of control during gluconeogenesis from lactate in the absence of glucagon

The concentration of lactate was $5 \mathrm{~mm}$ and that of Pyr $0.5 \mathrm{~mm}$. For other experimental details, see the legend to Tables 1 and 2. The flux control coefficients were calculated as described in the text. coefficient $(\%)$

PT

Pyruvate carboxylase

OAA transport

PEPCK

PK

Enolase/PGM/GAPDH/PGK $-17$

TIM/aldolase/fructose-1,6-bisphosphatase $\quad 27$ PGI/glucose-6-phosphatase 
Table 4. Distribution of control during gluconeogenesis from lactate in the absence or presence of glucagon

For experimental details, see the legend to Table 2 . The flux control coefficients were calculated as described in the text by using the following values for the elasticity coefficients of PT and OAA transport (OT):

$$
\epsilon_{\mathrm{Pyr}_{\mathrm{m}}}^{\mathrm{PT}_{\mathrm{T}}}=-6.1 \text { (see Table 1), } \epsilon_{\mathrm{OAA}_{\mathrm{m}}}^{\mathrm{OT}}=0.86, \epsilon_{\mathrm{OAA}_{\mathrm{c}}}^{\mathrm{OT}}=-0.74
$$

Flux control coefficient $(\%)$

\begin{tabular}{|c|c|c|c|c|c|}
\hline Step & $\begin{array}{l}5 \text { mM-Lactate } \\
\text { + glucagon }\end{array}$ & $\begin{array}{l}0.5 \mathrm{mM} \text {-Lactate } \\
\text { + glucagon }\end{array}$ & 5 mM-Lactate & $1 \mathrm{~mm}$-Lactate & $0.5 \mathrm{~mm}$-Lactate \\
\hline PT & 0.7 & 9 & 0.5 & 3 & 7 \\
\hline Pyruvate carboxylase & 83 & 89 & 56 & 72 & 75 \\
\hline OAA transport & 4 & 0.7 & 3 & 0.6 & 0.1 \\
\hline PEPCK & 8 & 0.7 & 5 & 0.8 & 0.2 \\
\hline PK & & & -18.6 & -15 & -8 \\
\hline Enolase/PGM/GAPDH/PGK & 0.3 & 0.3 & 32 & 12 & 9 \\
\hline $\begin{array}{l}\text { TIM/aldolase/fructose } \\
\text { 1,6-bisphosphatase }\end{array}$ & 3 & 0.2 & 27 & 8 & 7 \\
\hline $\begin{array}{l}\text { PGI/glucose-6- } \\
\text { phosphatase }\end{array}$ & $<0.1$ & $<0.1$ & 2 & 0.6 & 0.3 \\
\hline AT & & & 18 & 12 & 2 \\
\hline Sum & & & 125 & 94 & 100.6 \\
\hline
\end{tabular}

these conditions. In column 3 of Table 4 the values for the flux control coefficients when lactate was present at half-saturating concentrations are shown. We assumed that the elasticity coefficients of the Pyr transport system and of the transport of OAA under this condition were the same as in column 2 ( $5 \mathrm{~mm}$-lactate $/ 0.5 \mathrm{~mm}-\mathrm{Pyr})$. The higher elasticity coefficient of pyruvate carboxylase towards Pyr at the lower Pyr concentration leads to an increase in the flux control coefficient of the Pyr-transport system. There is little effect on the flux control coefficients of the other steps in the pathway. At lower gluconeogenic fluxes, too, most of the control is exerted by pyruvate carboxylase.

So far we have assumed that all flux-controlling steps were incorporated in the calculations, so that application of the summation theorem was correct. In order to check this, we measured the flux control coefficient of the AT, a step which might exert control on gluconeogenic flux by influencing the cytosolic ATP/ADP ratio. Carboxyatractyloside was used as a specific inhibitor of the translocator. Cells were perifused with $5 \mathrm{~mm}$-lactate $/ 0.5$ $\mathrm{mM}-\mathrm{Pyr} / 0.1 \mathrm{mM}$-oleate in the presence of $10 \mu \mathrm{M}$-carboxyatractyloside. Because of the slow permeation of the inhibitor into the cell (Stubbs et al., 1978), each time point in Fig. 5 represents a different intracellular amount of carboxyatractyloside, so that the flux control coefficient of the adenine-nucleotide translocator on gluconeogenesis is given by:

$$
C_{\mathrm{A} \text { Ilucose }}^{J_{\text {glux }}}=\frac{\left(\mathrm{d} J_{\text {glucose }} / J_{\text {glucose }}\right.}{\left(\mathrm{d} t / T_{\max }\right)}
$$

where $t$ refers to the time of incubation and $T_{\max }$ to the time needed to inhibit all translocator-related respiration, this being equivalent to the time required to fully inhibit gluconeogenesis (see Duszynski et al., 1982).

In the absence of glucagon the value for the flux control coefficient was $18 \%$. In the presence of the hormone, the control of flux by the AT almost disappeared, suggesting that the control on gluconeogenic flux by the translocator is exerted indirectly via PK. The fact that, in the absence of glucagon, flux control is exerted by a step outside the gluconeogenic pathway indicates that use of the summation theorem in Table 3 was not correct. The values in Table 3 could therefore be too high. Fortunately, the flux control coefficients of the steps that convert Pyr into PEP can be determined by an independent method.

Kacser \& Burns (1973) have shown that the flux control coefficient of an enzyme can be determined with an effector of the activity of the enzyme if the elasticity coefficient of the enzyme towards that effector is known:

$$
C_{\mathrm{E}_{j}}^{J}=\frac{C_{\mathrm{P}}^{J}}{\epsilon_{\mathrm{p}_{j}}^{v_{j}}}
$$

where $P$ refers to an effector. We have applied this approach by using Pyr as an effector.

Fig. 6 depicts gluconeogenic flux and the flux through the initial part of the gluconeogenic pathway in the absence of glucagon as a function of the extracellular Pyr concentration. From the lower curve the control by Pyr on gluconeogenic flux can be calculated. The shape of the upper curve is mainly determined by pyruvate carboxylase. However, since this enzyme does not fully control flux, we will, for the sake of completeness, consider the reactions that convert Pyr into PEP as one combined reaction. Since the flux through this combined reaction is not sensitive to its product, PEP, the elasticity coefficient of the combined reaction towards Pyr can be calculated from the upper curve in Fig. 6. Subsequently, by using eqn. (11), the flux control coefficient of the combined reaction on $J_{\text {glucose }}$ can be calculated. At low gluconeogenic fluxes, almost all control resides in the initial part of the pathway; when gluconeogenic flux increases and concomitantly, PK flux increases, the flux control coefficient of the initial part of the pathway decreases linearily to a minimum value of $65 \%$ under the condition with the highest lactate and Pyr concentrations (results not shown). By using the connectivity property together with the fact that the sum of the flux control 


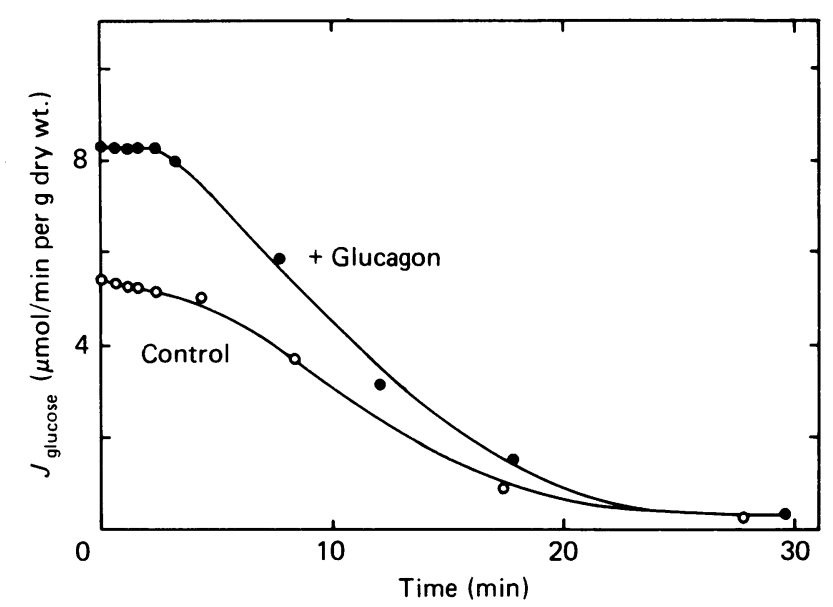

Fig. 5. Determination of the flux control coefficient of the AT on gluconeogenesis from lactate in the presence or absence of glucagon

Rat liver cells (200 mg dry wt.) were perifused with 5 mM-lactate / $0.5 \mathrm{~mm}$-Pyr $/ 0.1 \mathrm{~mm}$-oleate / $10 \mu \mathrm{M}$-carboxyatractyloside with or without $0.1 \mu \mathrm{M}$-glucagon for the times indicated in the Figure. The flow rate was $5.0 \mathrm{ml} / \mathrm{min}$. Glucose was assayed in the perifusate.

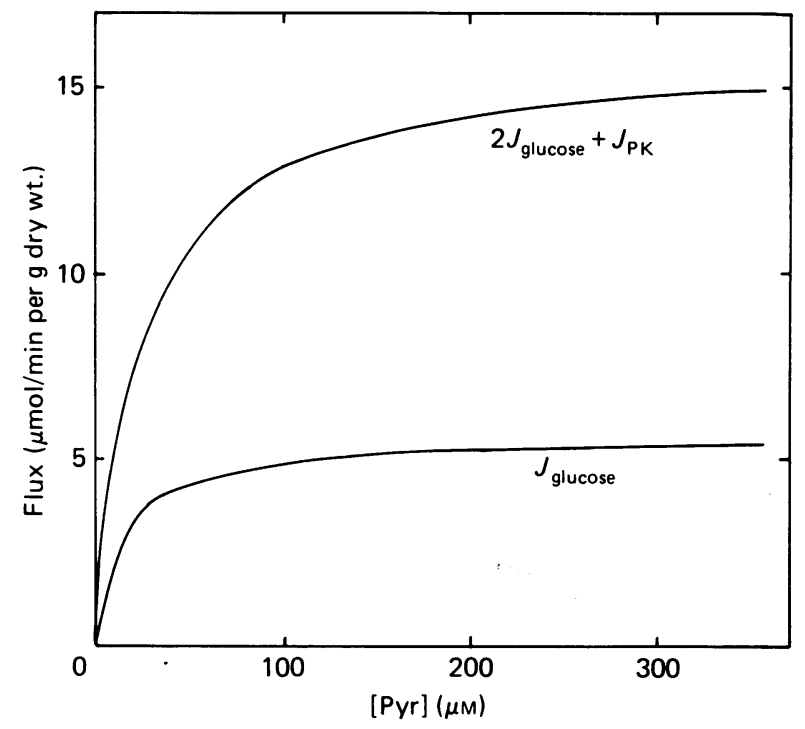

Fig. 6. Gluconeogenic flux and flux through the initial part of the gluconeogenic pathway in the absence of glucagon as a function of the extracellular Pyr concentration

For experimental details, see the legend to Table 2. The flux through the initial part of the pathway was calculated by multiplication of $J_{\text {glucose }}$ by 2 and addition of $J_{\mathrm{PK}}$. The latter was determined as described in Groen et al. (1983).

coefficients of the steps in the initial part of the pathway in this condition is $65 \%$, the individual values of the flux control coefficients can be calculated. As shown in Table 4 , column 4, the values are similar to those given in Table 3 . The values of the flux control coefficients of the other enzymes in the pathway could now be recalculated. These values are somewhat higher than those in Table 3. Together with the flux control coefficient of the AT, the sum of the flux control coefficients is $125 \%$, suggesting that there is additional negative flux control by steps outside the pathway. Possible candidates are the passive permeability of the mitochondrial membrane to protons and ATP-utilizing processes in the cytosol, such as the $\mathrm{Na}^{+} / \mathrm{K}^{+}$-ATPase.

Also given in Table 4 are the control distributions at lower, more physiological, concentrations of lactate. Again, we assumed that the elasticity coefficients of the PT and OAA-transport systems were the same as with $5 \mathrm{~mm}$-lactate and $0.5 \mathrm{~mm}$-Pyr. It is clear also that, at the lower gluconeogenic fluxes, control is distributed between different steps. Compared with the condition of $5 \mathrm{~mm}$ lactate and $0.5 \mathrm{~mm}-\mathrm{Pyr}$, two shifts have occurred in the control distribution. Owing to the higher elasticity coefficient of pyruvate carboxylase to Pyr, some control shifts from pyruvate carboxylase to the PT and the higher elasticity coefficient of the combined TIM/aldolase/ fructose-1,6-bisphosphatase reaction to GAP leads to a decrease of the flux control coefficient of this combined reaction.

\section{DISCUSSION}

In the present paper we have shown how the flux control coefficients of the steps in the gluconeogenic pathway can be calculated from the elasticity coefficients of the various enzymes and translocators to their respective substrates and products, provided that the magnitude of the flux through the different parts of the pathway is known. Compared with the qualitative approach used in most studies on control of gluconeogenesis, application of control analysis has the clear advantage that it enables one to estimate the importance of the flux-controlling enzymes relative to each other. Furthermore, because of the connectivity theorem, application of control analysis also allows one to understand why a certain enzyme exerts control and which kinetic properties of the pathway enzymes are important for the distribution of control.

Quantification of the variation in the values for the flux control coefficients given in Tables 3 and 4 is difficult, because, as explained above, the values of some elasticity coefficients are based on assumptions. In order to obtain insight into the influence of experimental error in the value of an elasticity coefficient on the values of the flux control coefficients, we have calculated the effect of a change in the value of an elasticity coefficient on the control distribution. A 2-fold change in the elasticity coefficient of PEPCK to PEP or the elasticity coefficient of fructose-1,6-bisphosphatase to Fru-1,6- $P_{2}$ has almost no effect $(<1 \%)$ on the flux control coefficients of the pathway enzymes, in both the presence or absence of glucagon, i.e. errors in the values of the elasticity coefficients of which we are most uncertain have no influence on the control distribution. A 2-fold change in the elasticity coefficient of pyruvate carboxylase to OAA would lead to a $15 \%$ change in the flux control coefficient of pyruvate carboxylase, and a $70 \%$ change in the flux control coefficients of OAA transport and PEPCK. A 2-fold change in the elasticity coefficient of pyruvate carboxylase to Pyr would induce a change in the value of $C_{\mathrm{PC}}^{\mathrm{J}}$ of about $15 \%$ and a compensatory change in control by pyruvate transport. In general, a change in the substrate elasticity coefficient of an enzyme has the largest effect on the flux control coefficients of the enzymes 
located before the affected enzyme, whereas a change in the product elasticity coefficient primarily affects the flux control coefficients of the enzymes downstream. If an enzyme is located in a branch of a pathway, the effect of a change in the value of an elasticity coefficient is distributed more evenly among the enzymes in the main branch of the pathway. For instance, a 2-fold change in the elasticity coefficient of pyruvate kinase to PEP changes the flux control coefficient of all pathway enzymes in the absence of glucagon by about $30 \%$; the values of the flux control coefficients of the enzymes in the initial part of the pathway change in the same direction as that of pyruvate kinase, whereas the flux control coefficients of the enzymes in the remainder of the pathway change in the opposite way.

The elasticity coefficients of near-equilibrium enzymes are a simple function of the $\Gamma / K_{\text {eq }}$. ratio and can be determined relatively easily. If, however, the enzyme under consideration is very close to equilibrium, experimental error in the determination of the mass-action ratio can lead to a large variation in the value for the elasticity coefficient. A change in the values of the elasticity coefficients of a near-equilibrium enzyme induces a proportional change in the flux coefficient of the enzyme. This change is compensated for by a change in the flux control coefficients of the enzymes located after the near-equilibrium step. Hence a change in the elasticity coefficients of the enzymes located betwen PEP and GAP has almost no effect on the flux control coefficients of pyruvate carboxylase and $\mathrm{PK}$, for instance, but changes the flux control coefficients of the enzymes located between GAP and glucose.

In conclusion, the values of the flux control coefficients of the non-equilibrium enzymes are not very sensitive to changes in the values of their elasticity coefficients. The influence of experimental error is greater in the case of near-equilibrium enzymes. In general this will have no great influence on the control distribution, since in most cases near-equilibrium enzymes do not exert significant control. In the particular case of gluconeogenesis in the absence of glucagon, the near-equilibrium enzymes between PEP and GAP do exert significant control. Therefore some variation in the value of the flux control coefficient of the combined TIM/aldolase/fructose 1,6-bisphosphatase reaction has to be taken into account.

What new information have we obtained by this quantitative interpretation of experimental data, most of which has been published previously?

(1) We have now been able to verify the suggestion made by Groen et al. (1983) about the central role of pyruvate carboxylase in the control of gluconeogenesis. The flux control coefficient of PEPCK is low under the conditions used. Only strong product inhibition of pyruvate carboxylase by OAA can increase the flux control coefficient of PEPCK. Such an increase in the concentration of $\mathrm{OAA}_{\mathrm{m}}$ will only occur if the activity of PEPK decreases in such a way that the $V_{\text {max }}$. becomes lower than the $V_{\max }$ of pyruvate carboxylase.

(2) As expected, activity of PK induces a shift in the distribution of control. However, to our surprise, the enzyme itself exerts relatively little control. This is due to the high value of the elasticity coefficient of PK to PEP. On the other hand the high value of $\epsilon_{\mathrm{PEP}}^{\mathrm{PK}}$ makes all steps that exert control on the PEP concentration effective regulators of PK flux and thus gluconeogenic flux. An example of this type of regulation is given in Fig. 2. A decrease in the cytosolic $\mathrm{NADH} / \mathrm{NAD}^{+}$ratio leads to an increase in the PEP concentration and thus to a stimulation of flux through the PEP/Pyr cycle (see also Sistare \& Haynes, 1985). This substrate cycle transports reducing equivalents from the mitochondria to the cytosol. Apparently the maintenance of a reduced cytosolic compartment is more important than a high rate of gluconeogenesis. Indeed, it has been shown that, when glucagon is added under highly oxidized conditions, the hormone does not stimulate, but actually inhibits, gluconeogenic flux (Rognstad, 1975; Mapes \& Harris, 1976; Claus \& Pilkis, 1977).

(3) At saturating concentrations of Pyr, Pyr transport exerts almost no control on gluconeogenic flux (see also Halestrap \& Armston, 1984). However, at lower pyruvate concentrations, the elasticity coefficient of pyruvate carboxylase to Pyr is much higher than at high concentrations of the substrate, leading to shift in control from pyruvate carboxylase to Pyr transport (Table 4). Hence at lower Pyr concentrations the transport system probably does control gluconeogenic flux to a significant extent.

(4) Unexpectedly, the near-equilibrium enzymes between PEP and GAP do exert control in the absence of glucagon. This confirms the prediction of Kacser \& Burns (1973) that near-equilibrium enzymes can, under some conditions, control flux.

(5) Another unexpected result was the observation that, in the absence of glucagon, the flux control coefficient of the combined TIM/aldolase/fructose 1,6-bisphosphatase reaction was of the same order of magnitude as that of the combined reactions between PEP and GAP. This is caused by the kinetic properties of aldolase, reflected by the sigmoidal relationship between $J_{\text {glucose }}$ and GAP (Groen et al., 1983).

Can these results be extrapolated to the situation in vivo? In the intact animal, lactate is the predominant gluconeogenic substrate. The concentration in the blood ranges between 0.6 and $2 \mathrm{mM}$, depending on the nutritional state (Hue, 1981; Hers \& Hue, 1983). Under 'fasted' conditions, the concentration is around $1 \mathrm{~mm}$. Gluconeogenesis will then operate at about $70 \%$ of the maximal capacity. The lactate concentration will therefore exert some control on the flux. Major control will be exerted by pyruvate carboxylase. Since the glucagon level is high in the fasted state, PK activity will be low, and little control of flux will be exerted by the other steps in the gluconeogenic pathway. Some gluconeogenesis will occur from substrates such as glycerol, asparagine and glutamine, which enter the pathway after pyruvate carboxylase, so that some control on total glucose output can be exerted by the steps that are involved in the catabolism of these substrates.

Under 'fed' conditions PK is active (Feliu et al., 1976; Riou et al., 1976; Van Berkel et al., 1976) and consequently, if there is gluconeogenesis, flux control will be distributed between many steps in the pathway. This fine control is important, since gluconeogenic flux must be kept to a minimum under these conditions. Under fed conditions the Glc-6-P/Glc and the Fru-1,6- $P_{2} /$ Fru-6- $P$ cycles are probably also active (Hue, 1981; Hers \& Hue, 1983). If the flux through the limbs of the cycles can be quantified, the flux control coefficients of the cycle enzymes and of the other pathway enzymes can be calculated (Regen \& Pilkis, 1984; Fell \& Sauro, 1985).

A potential controlling factor in the fed state is 
Fru-2,6- $P_{2}$. By influencing the flux through the Fru$1,6-P_{2} /$ Fru-6- $P$ cycle, this allosteric effector can, in principle, exert considerable control on the concentration of Fru-1,6- $P_{2}$ and thus on PK flux. Further studies may reveal whether this is indeed the case.

This study was supported by a grant from the Netherlands Organization of the Advancement of Pure Research (Z.W.O.) under the auspices of the Netherlands Foundation for Chemical Research (S.O.N.). We are grateful to Ms. G. E. E. van Noppen and Ms. G. C. Klebach for their help in preparing the manuscript.

\section{REFERENCES}

Adam, P. A. J. \& Haynes, R. C. (1969) J. Biol. Chem. 244, 6444-6450

Akerboom, T. P. M., Krietsch, W. K. G., Kuntz, G. \& Sies, H. (1979) FEBS Lett. 105, 90-94

Allan, E. H., Chisholm, A. B. \& Titheradge, M. A. (1983) Biochem. J. 212, 417-426

Atkinson, M. R., Jonson, E. \& Morton, R. K. (1961) Biochem. J. 79, 12-15

Barden, R. E., Fung, C. H., Utter, M. F. \& Scrutton, M. C. (1972) J. Biol. Chem. 247, 1323-1333

Bergmeyer, H. U. (ed.) (1970) Methoden der Enzymatischen Analyse, 2nd ed., Verlag Chemie, Weinheim

Cassaza, J. P., Stone, S. R. \& Fromm, H. J. (1979) J. Biol. Chem. 254, 4661-4665

Claus, T. H. \& Pilkis, S. J. (1977) Arch. Biochem. Biophys. 182 $52-63$

Duszysnki, J., Groen, A. K., Wanders, R. J. A., Vervoorn, R. C. \& Tager, J. M. (1982) FEBS Lett. 146, 116-119

Feliu, J. E., Hue, L. \& Hers, H. G. (1976) Proc. Natl. Acad. Sci. U.S.A. 73, 2762-2766

Fell, D. A. \& Sauro, H. M. (1985) Eur. J. Biochem. 198 , 555-561

Friedmann, N. (1984) Physiol. Rev. 64, 170-259

Groen, A. K. (1984) Ph.D. Thesis, University of Amsterdam

Groen, A. K., Sips, H. J., Vervoorn, R. C. \& Tager, J. M. (1982a) Eur. J. Biochem. 122, 87-93

Groen, A. K., Vervoorn, R. C., Wanders, R. J. A., Van der Meer, R. \& Tager, J. M. (1982b) Biochim. Biophys. Acta 721 , $172-177$

Groen, A. K., Van der Meer, R., Westerhoff, H. V., Wanders, R. J. A., Akerboom, T. P. M. \& Tager, J. M. (1982c) in Metabolic Compartmentation (Sies, H., ed.), pp. 9-37, Academic Press, New York

Groen, A. K., Vervoorn, R. C., Van der Meer, R. \& Tager, J. M. (1983) J. Biol. Chem. 258, 14346-14353

Halestrap, A. P. (1978) Biochem. J. 172, 377-387
Halestrap, A. P. \& Armston, A. E. (1984) Biochem. J. 223, 677-685

Heinrich, R. \& Rapoport, T. A. (1974) Eur. J. Biochem. 42, 89-95

Hers, H. G. \& Hue, L. (1983) Annu. Rev. Biochem. 52, 617-653

Hoek, J. B., Nicholls, D. G. \& Williamson, J. R. (1980) J. Biol. Chem. 155, 1458-1464

Hue, L. (1981) Adv. Enzymol. Relat. Areas Mol. Biol. 52, 249-331

Jomain-Baum, M., Schramm, V. L. \& Hanson, R. W. (1976) J. Biol. Chem. 251, 37-44

Kacser, H. (1983) Biochem. Soc. Trans. 11, 35-40

Kacser, H. \& Burns, J. A. (1973) in Rate Control of Biological Processes (Davies, D. D., ed.), pp. 65-104, Cambridge University Press, London

Kacser, H. \& Burns, J. A. (1979) Biochem. Soc. Trans. 7, 1149-1161

Lowry, O. H. \& Passoneau, J. V. (1964) J. Biol. Chem. 239, $31-42$

Lowry, O. H. \& Passoneau, J. V. (1971) A Flexible System in Enzymatic Analysis, Academic Press, New York

Mapes, J. P. \& Harris, R. A. (1976) J. Biol. Chem. 251, 6189-6196

Regen, D. M. \& Pilkis, S. J. (1984) J. Theor. Biol. 111, 635-658

Riou, J. P., Claus, T. H. \& Pilkis, S. J. (1976) Biochem. Biophys. Res. Commun. 73, 591-599

Rognstad, R. (1975) Biochem. Biophys. Res. Commun. 63, 900-905

Rolleston, F. S. (1972) Curr. Top. Cell Regul. 5, 47-75

Rolleston, F. S. \& Newsholme, E. A. (1967) Biochem. J. 104, 524-533

Siess, E. A., Brocks, D. G., Lattke, H. K. \& Wieland, O. H. (1978) Hoppe-Seyler's Z. Physiol. Chem. 359, 785-798

Sips, H. J., Groen, A. K. \& Tager, J. M. (1980) FEBS Lett. 119, 271-274

Sistare, F. D. \& Haynes, R. C. (1985) J. Biol. Chem. 260, 12748-12753

Soboll, S., Elbers, R., Scholz, R. \& Heldt, H. W. (1980) Hoppe-Seyler's Z. Physiol. Chem. 361, 69-76

Sols, A. \& Marco, R. (1970) Curr. Top. Cell. Regul. 2, 227-273

Stubbs, M., Vignais, P. V. \& Krebs, H. A. (1978) Biochem. J. 172, 333-342

Tischler, M. E. Hecht, P. \& Williamson, J. R. (1977) Arch. Biochem. Biophys. 181, 278-292

Van Berkel, T. J. C., Kruyt, J. K., Koster, J. F. \& Hülsmann, W. C. (1976) Biochem. Biophys. Res. Commun. 72, 917-925

Van der Meer, R., Akerboom, T. P. M., Groen, A. K. \& Tager, J. M. (1978) Eur. J. Biochem. 84, 321-428

Williamson, J. R. (1965) J. Biol. Chem. 240, 2308-2321

Williamson, J. R. \& Corkey, B. E. (1969) Methods Enzymol. 13, 434-513

Williamson, J. R., Browning, E. T. \& Scholz, R. (1969) J. Biol. Chem. 244, 4607-4616

Wood, H. G., Davis, J. J. \& Lockmüller, H. (1966) J. Biol. Chem. 241, 5692-5704 